\title{
Evaluation of safety and efficacy of elective PCI in patients with cardiac insufficiency
}

\author{
JIANG-XIN JING ${ }^{1}$, XIAO-LAN ZHONG ${ }^{2}$ and SHENG-GUO CHEN ${ }^{3}$ \\ ${ }^{1}$ Ultrasound Room and ${ }^{2}$ Department of Cardiology, The Second Affiliated Hospital of Xinjiang Medical University, \\ Urumqi, Xinjiang 830063; ${ }^{3}$ Department of Anatomy, School of Basic Medical Sciences, \\ Xinjiang Medical University, Urumqi, Xinjiang 830011, P.R. China
}

Received April 11, 2016; Accepted November 25, 2016

DOI: $10.3892 /$ etm.2016.4005

\begin{abstract}
We analyzed the safety and the efficacy of the treatment with elective percutaneous coronary intervention (PCI) in patients with coronary heart disease complicated with cardiac insufficiency. We enrolled 217 patients diagnosed with chronic ischemic heart disease complicated with cardiac failure. According to the type of treatment they received, patients were divided into 3 groups: i) The conservative treatment group with 60 patients (they received standard medication); ii) the early PCI group with 82 cases (their condition was stabilized, surgical risk was assessed and PCI was taken as early as possible); and iii) the advanced PCI group with 75 cases (ischemic myocardium was corrected and then elective PCI was applied and for aggravated myocardial ischemia cases, PCI was applied after assessing the risk of surgery). Follow-up visits were set for approximately 3 years and clinical outcomes were compared. Our results showed that the survival time in the early PCI group was significantly prolonged and the survival rate was considerably increased during 3 years. Left ventricular ejection fraction in the early PCI group markedly increased and left ventricular end-diastolic diameter and pro-BNP level decreased significantly. The occurrence rates of perioperative complications in the early PCI group and major adverse cardiac events (MACE) during the follow-up period were significantly reduced. Quality of life scores in the early PCI group markedly improved. We concluded that in patients with coronary heart disease complicated with cardiac insufficiency, early PCI treatment was safe and effective.
\end{abstract}

\section{Introduction}

Chronic ischemic coronary heart disease is the most common underlying cause of acute and chronic cardiac failure (1).

Correspondence to: Dr Sheng-Guo Chen, Department of Anatomy, School of Basic Medical Sciences, Xinjiang Medical University, 393 Xinyi Road, Urumqi, Xinjiang 830011, P.R. China

E-mail: chen_shengguo1@163.com

Key words: coronary heart disease, complicated with cardiac insufficiency, percutaneous coronary intervention, safety, efficiency
Results obtained from studies realized by Crusade, Brig and COMMIT/CCS-2 (2) revealed that 1 in 4 patients suffered from coronary heart disease complicated with cardiac failure. Two-thirds of patients with coronary disease who were treated with conventional percutaneous coronary intervention (PCI), were suffering from cardiac insufficiency to varying degrees (3). Treatment guidelines for cardiac failure from ACC/AHA published in 2013 and the diagnostic guidelines for ESC acute and chronic heart failure published in 2012 suggested the existence of indications (IC) of CABG or PCI in patients with left ventricular dysfunction who still felt angina and with right coronary artery anatomy after accepting and following GDMT guidelines (4). ESC Guidelines of coronary revascularization published in 2014 showed a poor prognosis for patients with cardiac failure symptoms after a sufficient amount of drug therapy (5). The study strongly recommended further revascularization strategies and more intensive drug therapy to improve hemodynamics index and prognosis. Nevertheless, it is difficult to make a decision on the timing of PCI.

Further studies are crucial to have a better understanding on whether to emphasize the maximization of drug treatment primarily or employ PCI treatment as early as possible. This, of course, should be under the premise of fully assessing all involved risks. This study summarized the outcome of controlled clinical trials designed by the Second Affiliated Hospital of Xinjiang Medical University in order to provide more rational treatment strategies for patients suffering from coronary heart disease complicated with cardiac insufficiency.

\section{Materials and methods}

Object data. From January 2012 to January 2013, we enrolled 217 patients diagnosed with chronic ischemic coronary heart disease complicated with cardiac insufficiency. According to the type of treatment they received, patients were divided into 3 groups: i) The conservative treatment group with 60 patients (they received ordinary medication); ii) the early PCI group with 82 cases (their condition was stabilized, surgical risk was assessed and PCI was taken as early as possible); and iii) the advanced PCI group with 75 cases (ischemic myocardium was corrected and then elective PCI was applied and for aggravated myocardial ischemia cases, PCI was 
Table I. Comparison of baseline data among 3 groups.

\begin{tabular}{|c|c|c|c|c|c|c|c|c|}
\hline Groups & $\begin{array}{c}\text { Case } \\
\text { no. }\end{array}$ & Male/female & $\begin{array}{l}\text { Average age } \\
\text { (years) }\end{array}$ & $\begin{array}{l}\text { Duration of } \\
\text { ischemia } \\
\text { (years) }\end{array}$ & $\begin{array}{l}\text { Acute heart } \\
\text { failure, } \\
\text { case }(\%)\end{array}$ & $\begin{array}{l}\text { Classification } \\
\text { (Killip) }\end{array}$ & $\begin{array}{c}\text { Chronic } \\
\text { heart failure, } \\
\text { case }(\%)\end{array}$ & $\begin{array}{c}\text { Classification } \\
\text { (NYHA) }\end{array}$ \\
\hline $\begin{array}{l}\text { Conservative } \\
\text { treatment }\end{array}$ & 60 & $36 / 24$ & $65.4 \pm 12.6$ & $4.2 \pm 1.3$ & $12(20.0)$ & $1.6 \pm 0.5$ & $48(80.0)$ & $2.2 \pm 0.6$ \\
\hline Early PCI & 82 & $46 / 36$ & $64.8 \pm 13.5$ & $4.4 \pm 1.5$ & $18(22.0)$ & $1.7 \pm 0.6$ & $64(78.0)$ & $2.3 \pm 0.8$ \\
\hline Advanced PCI & 75 & $39 / 36$ & $65.3 \pm 14.2$ & $4.3 \pm 1.6$ & $15(20.0)$ & $1.6 \pm 0.4$ & $60(80.0)$ & $2.2 \pm 0.7$ \\
\hline F-value $\left(\chi^{2}\right)$ & & 0.871 & 0.632 & 0.329 & 0.118 & 0.847 & 0.118 & 0.947 \\
\hline P-value & & 0.647 & 0.525 & 0.217 & 0.943 & 0.636 & 0.943 & 0.828 \\
\hline
\end{tabular}

PCI, percutaneous coronary intervention; NYHA, The New York Heart Association.

operated after assessing the risk of surgery). We obtained permission from the Ethics Committee of the Second Affiliated Hospital of Xinjiang Medical University hospital and informed consent of patients or their families.

Exclusion criteria were: i) Patients with heart failure caused by valvular heart diseases; ii) those with primary cardiomyopathy and congenital heart disease; iii) patients with acute coronary syndrome complicated with heart failure; iv) cases with clear right heart failure; v) those with severe hypertension and diabetes with out-of-control standards; vi) those with complicated cerebral vascular diseases; vii) patients with severe liver and kidney dysfunction; viii) patients with coagulation disorders and severe angina diagnosed by emergency treatment of PCI or CABG; ix) patients with severe heart failure with poor prognosis; $x$ ) cases with allergic to contrast medium; xi) those who cannot be prescribed medication; and xii) patients with poor compliance and those with inadequate follow-up data. Comparison of baseline data among the three groups revealed no statistically significant differences $(\mathrm{P}>0.05)$ (Table I).

Therapeutic method. All the patients were given intensive drug treatment including anti-myocardial ischemia, antiplatelet, anticoagulant, lipid-lowering therapy, anti-inflammatory, antihypertensive treatment, blood glucose control medication, anti-ventricular remodeling, positive inotropic drugs and vasoactive drugs. We also used diet management (controlling sodium and water intake) and reasonable exercise. Additionally, cardiac assistance devices such as intra-aortic balloon counterpulsation for patients with unstable condition were employed. Use of assisted ventilation was considered for patients with respiratory difficulties, and bedside hemofiltration surgery was considered to treat patients with acute renal failure. Patients in the conservative treatment group were intensively monitored for changes in condition and this was done only under the basis of strict medical treatment. Emergency PCI or CABG surgery was implemented in the context of a full assessment for intervention and risks of surgical operation.

Patients in the early PCI group were assessed by PCI, using the GRACE scoring system (2). For low-risk and moderate-risk patients were assessed for implementing intervention therapy as early as possible. For high-risk patients, this was combined with the SYNTAX scoring system and a comprehensive assessment was used. In the advanced PCI group, elective PCI was selected after evaluating the intervention risks. Under aggravated conditions with poor drug therapy, emergency PCI or CABG surgery was selected after a full evaluation. For every patient in each group, we obtained informed consent from patients or their families.

Observational index. Patients participated in follow-up examinations for 3 years on average. We compared the survival rate, left ventricular ejection fraction (LVEF), left ventricular end-diastolic diameter (LVEDD) and pro-BNP level. We also compared perioperative complications and the occurrence rate of major adverse cardiac events (MACE) during the follow-up period. Differences in life quality score were also compared. Pro-BNP was tested using ELISA [kits were provided by Shanghai Hufeng Biotechnology Co., Ltd. (Shanghai, China)]. Seattle Angina Questionnaire (SAQ) was used as a reference to test the life quality score which included five major items and 19 entries, the higher the score, the better the quality of life.

Statistical analysis. SPSS 20.0 (IBM SPSS, Armonk, NY, USA) was used for data analysis. Quantitative data were reported as mean \pm standard deviation and comparisons among many groups were made using single-factor ANOVA. Comparisons between groups were conducted using the independent sample t-test and qualitative data were expressed as number of cases or a percentage. Comparisons among groups were made using $\chi^{2}$ test and the survival period was calculated using the Kaplan-Meier (KM) method (log-rank test). $\mathrm{P}<0.05$ was considered to indicate a statistically significant difference.

\section{Results}

Comparison of survival rates during a period of 3-years. The median survival time in the early PCI group, the advanced PCI group and the conservative treatment group was 38, 36 and 33 months, respectively. Median survival time was significantly longer in the early PCI group $\left(\chi^{2}=171.610, \mathrm{P}<0.001\right)$ (Fig. 1). During the 3-year follow-up we recorded 16 cases of cardiac death in the early PCI group (19.5\%), 22 cases in the advanced PCI group (29.3\%) and 35 cases died in the conservative treatment group (58.3\%). The 3-year survival rate in the early PCI group was significantly increased and the difference had statistical significance $\left(\chi^{2}=24.343, \mathrm{P}<0.001\right)$. 
Table II. Comparison among LVEF, LVEDD and pro-BNP levels.

\begin{tabular}{|c|c|c|c|c|c|c|}
\hline \multirow[t]{2}{*}{ Groups } & \multicolumn{2}{|c|}{$\operatorname{LVEF}(\%)$} & \multicolumn{2}{|c|}{ LVEDD (mm) } & \multicolumn{2}{|c|}{ pro-BNP (pg/ml) } \\
\hline & $\begin{array}{c}\text { Before } \\
\text { treatment }\end{array}$ & $\begin{array}{c}\text { After } \\
\text { treatment }\end{array}$ & $\begin{array}{c}\text { Before } \\
\text { treatment }\end{array}$ & $\begin{array}{c}\text { After } \\
\text { treatment }\end{array}$ & $\begin{array}{c}\text { Before } \\
\text { treatment }\end{array}$ & $\begin{array}{c}\text { After } \\
\text { treatment }\end{array}$ \\
\hline $\begin{array}{l}\text { Conservative } \\
\text { treatment }\end{array}$ & $38.6 \pm 5.2$ & $43.4 \pm 3.4$ & $58.2 \pm 2.4$ & $56.7 \pm 2.4$ & $1256.4 \pm 42.6$ & $864.5 \pm 32.9$ \\
\hline Early PCI & $37.7 \pm 5.5$ & $55.2 \pm 3.3$ & $58.6 \pm 2.5$ & $53.2 \pm 2.5$ & $1320.6 \pm 46.5$ & $524.6 \pm 34.2$ \\
\hline Advanced PCI & $38.2 \pm 5.3$ & $48.5 \pm 3.5$ & $58.5 \pm 2.3$ & $55.8 \pm 2.6$ & $1274.5 \pm 48.2$ & $720.3 \pm 35.7$ \\
\hline F-value & 0.626 & 7.624 & 0.963 & 6.549 & 0.526 & 6.754 \\
\hline P-value & 0.532 & $<0.001$ & 0.754 & $<0.001$ & 0.423 & $<0.001$ \\
\hline
\end{tabular}

LVEF, left ventricular ejection fraction; LVEDD, left ventricular end-diastolic diameter; PCI, percutaneous coronary intervention.

Table III. Comparison of occurrence rate of perioperative complications and MACE, proportion (\%).

\begin{tabular}{|c|c|c|c|c|c|c|c|c|c|c|}
\hline Groups & $\begin{array}{c}\text { Exacerbation } \\
\text { of heart } \\
\text { failure }\end{array}$ & $\begin{array}{c}\text { Acute renal } \\
\text { failure and } \\
\text { respiratory } \\
\text { failure }\end{array}$ & Death & $\begin{array}{c}\text { Severe } \\
\text { hemorrhage }\end{array}$ & $\begin{array}{l}\text { Surgical } \\
\text { failure }\end{array}$ & $\begin{array}{l}\text { Perioperative } \\
\text { complications }\end{array}$ & $\begin{array}{c}\text { Exacerbation } \\
\text { of heart } \\
\text { failure }\end{array}$ & $\begin{array}{c}\text { Recurrence } \\
\text { of angina } \\
\text { pectoris }\end{array}$ & $\begin{array}{c}\text { Target } \\
\text { vessel } \\
\text { revascularization }\end{array}$ & $\begin{array}{l}\text { MACE } \\
\text { occurrence } \\
\text { rate }\end{array}$ \\
\hline $\begin{array}{l}\text { Conservative } \\
\text { treatment }\end{array}$ & 5 & 2 & 3 & 2 & 6 & $18(81.8)$ & 10 & 13 & 10 & $33(55.0)$ \\
\hline Early PCI & 4 & 2 & 2 & 2 & 2 & $12(14.6)$ & 8 & 5 & 6 & $19(23.2)$ \\
\hline $\begin{array}{l}\text { Advanced } \\
\text { PCI }\end{array}$ & 9 & 4 & 3 & 3 & 4 & $23(30.7)$ & 10 & 10 & 10 & $30(40.0)$ \\
\hline$\chi^{2}$ & & & & & & 37.635 & & & & 15.170 \\
\hline P-value & & & & & & $<0.001$ & & & & 0.001 \\
\hline
\end{tabular}

MACE, major adverse cardiac events; PCI, percutaneous coronary intervention.

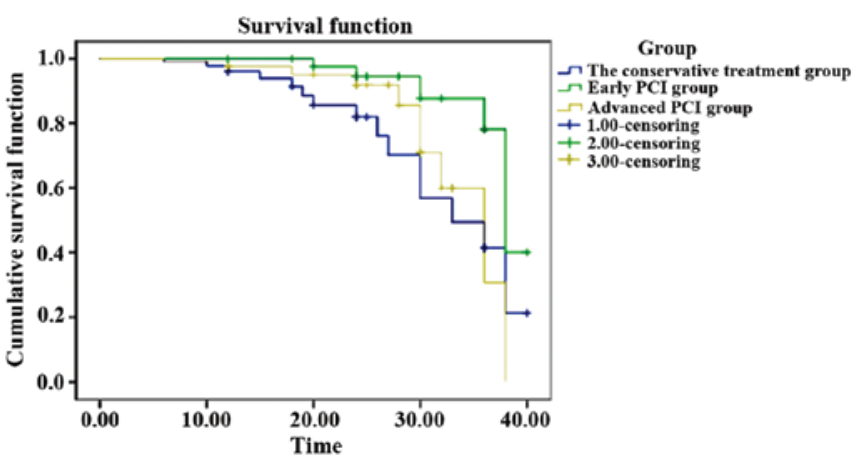

Figure 1. Kaplan-Meier analysis of survival time.

Comparison among LVEF, LVEDD and pro-BNP levels. LVEF in patients in all three groups was improved after treatment, while LVEDD and pro-BNP levels both decreased. The early PCI group had improved more significantly and all differences were statistically significant $(\mathrm{P}<0.05)$ (Table II).

Comparison of occurrence rate of perioperative complications and MACE. There were 15 cases of emergency PCI and 7 cases of CABG in the conservative treatment group. In the advanced PCI group, we had 56 cases of normal elective PCI, 13 cases of emergency treatment in PCI and 6 cases of
CABG. In the conservative treatment group we had several perioperative complications with the occurrence rate of 22 . Perioperative complications and MACE occurrence rate during the follow-up period were significantly reduced in the conservative treatment group and the difference had statistical significance $(\mathrm{P}<0.05)$ (Table III).

Comparison of life quality score. The average life quality score for the conservative treatment group, the early PCI group and the advanced PCI group was $68.7 \pm 9.2,82.5 \pm 10.3$ and $75.4 \pm 13.6$, respectively. Life quality score in the early PCI group improved significantly and the difference had statistical significance $(\mathrm{F}=10.325, \mathrm{P}=0.007)$.

\section{Discussion}

It has been shown that revascularization may bring benefit to cardiac patients (6) by restoring the normal function after improving ischemia. Physiological mechanisms of heart failure are mainly ventricular remodeling (geometric structure, quality and capacity) which manifest itself from a few days to a few months. Patients with serious cardiac insufficiency caused by ACS complicated with severe heart failure, chronic ischemic heart disease and coronary heart disease associated with other types of heart disease (valvular heart disease) can 
benefit from elective PCI (7). For patients with severe heart failure and adequate drug therapy (ACET class, $\beta$-blockers, aldosterone receptor antagonists and diuretics) is essential and blood supply recanalization on myocardial salvage is necessary for improving their cardiac function (8). However, interventional treatment for such patients should be initiated only after full consideration of various factors and after developing a detailed plan for interventional therapy. Risks involved with the therapy should be explained to patients' families and suitable percutaneous intervention support equipment (IABP, ECMO) should be considered to save myocardium and improve heart function (9). Guidelines for myocardial revascularization of ESC/EACTS published in 2014 suggested that, patients with stable angina or silent myocardial ischemia can be treated with PCI (IA) (5). Left ventricular systolic dysfunction (ejection fraction $\leq 35 \%$ ) in patients with chronic heart failure could be treated with PCI. Interventional treatment of severe heart failure needs to ensure the safety of patients during the pre-, intra- and post-operation periods in order to improve the prognosis. There are six important elements to be considered: i) Puncture pathway: Femoral artery may be the most appropriate site (10). Radial artery is another option, considering the tolerance of patients. ii) Use of anticoagulants: Appropriate anticoagulant therapy depends on the type of surgical intervention, type of drug and mechanical devices. Anticoagulant treatment used in general high-risk interventions is similar to the method used in conventional interventions. The activated coagulation time in such patients must be maintained over $300 \mathrm{sec}$ using unfractionated heparin (11). Aspirin should be administered routinely, while thienopyridine-type drugs (clopidogrel, ticagrelor) through stent implantation are routinely used. iii) Operation time: Patients with severe illness and poor tolerance need shortening of the operation time, thus it may be a proper choice to perform an intense intervention in large blood supply area and vessels influencing cardiac function. This intervention should especially be focused on the left anterior descending revascularization, partial revascularization or stage revascularization (12). iv) The type and amount of contrast agent: The contrast agent selection may play an important role in reducing the risks involved in surgical intervention for high-risk patients (13). Isotonic and non-ionic contrast agents may cause few side effects such as hemodynamics and kidney damage, while they are better tolerated by high-risk patients. The dose of contrast agent should be minimized during the operation because excessive use of the agent within a short period of time may lead to acute pulmonary edema. v) Sedation applications: Strengthening sedation before, during and after operation is important to catatonics. Morphine is a proper sedative with certain effect on the prevention and the treatment of acute pulmonary edema. Patients with pulmonary edema can use a ventilator. The curative effect is good, and the safety and success rate of the operation is high (14). vi) Use of medication: Drug use after operation and during the follow-up period must be strictly controlled, which is important to single patency artery intervention. The single patency artery often has a large area of blood supply and supplies the occlusive artery through collateral vessels. Once the acute or subacute occlusion occurs, it can be fatal to patients (15).

In summary, results have shown that the early PCI group survival time was prolonged significantly and the 3-year survival rate was increased as well. Mortality rate increased in the conservative group. During the treatment and follow-up period, the rate of emergency intervention or operative treatment reached $36.7 \%$, which probably was the main reason for the perioperative complication rate increase. Perioperative complications and the follow-up MACE rate in the early PCI group were reduced significantly. Worsening heart condition, heart failure and operation failure were the main perioperative complications observed during the study. This finding suggested the probability of an increased risk in patients who had emergency intervention or operation for their cardiac insufficiency. LVEF of the early PCI group increased significantly, while the LVEDD and pro-BNP level clearly decreased. This result suggested that PCI should conduct reversible ventricular remodeling and improve heart function as early as possible. Moreover, the life quality score in the early PCI group was improved significantly, which greatly improved the long-term life quality of heart failure patients. We concluded that the early PCI treatment in coronary artery disease patients with heart dysfunction is safe and effective.

\section{References}

1. Dokainish H, Teo K, Zhu J, Roy A, AlHabib KF, ElSayed A, Palileo-Villaneuva L, Lopez-Jaramillo P, Karaye K, Yusoff K, et al; INTER-CHF Investigators: Heart failure in Africa, Asia, the Middle East and South America: the INTER-CHF study. Int J Cardiol 204: 133-141, 2016.

2. Edwards J, Goodman SG, Yan RT, Welsh RC, Kornder JM, Deyoung JP, Chauret D, Picard JP, Eagle KA and Yan AT: Has the ClOpidogrel and metoprolol in myocardial infarction trial (COMMIT) of early $\beta$-blocker use in acute coronary syndromes impacted on clinical practice in Canada? Insights from the Global Registry of Acute Coronary Events (GRACE). Am Heart J 161: 291-297, 2011.

3. Whayne TF, Saha SP, Quevedo K and Mukherjee D: Optimal medical therapy for coronary artery disease in 2011 - perspectives from the STICH Trial. Cardiovasc Hematol Agents Med Chem 9: 269-276, 2011.

4. Lopez-Jimenez F, Simha V, Thomas RJ, Allison TG, Basu A, Fernandes R, Hurst RT, Kopecky SL, Kullo IJ, Mulvagh SL, et al: A summary and critical assessment of the 2013 ACC/AHA guideline on the treatment of blood cholesterol to reduce atherosclerotic cardiovascular disease risk in adults: filling the gaps. Mayo Clin Proc 89: 1257-1278, 2014.

5. Costa F, Ariotti S, Valgimigli M, Kolh P and Windecker S; Task Force on Myocardial Revascularization of the European Society of Cardiology (ESC) and the European Association for Cardio-Thoracic Surgery (EACTS): Perspectives on the 2014 ESC/EACTS Guidelines on myocardial revascularization: fifty years of revascularization: where are we and where are we heading? J Cardiovasc Transl Res 8: 211-220, 2015.

6. Li LQ, Liu XH, Zhang J, Lai CL and He YX: Influences of percutaneous coronary intervention on myocardial activity in myocardial infarction patients with different viable myocardium. Zhonghua Nei Ke Za Zhi 52: 811-814, 2013 (In Chinese).

7. Gurunathan S, Ahmed A and Senior R: The benefits of revascularization in chronic heart failure. Curr Heart Fail Rep 12: 112-119, 2015.

8. Cleland JG, Calvert M, Freemantle N, Arrow Y, Ball SG, Bonser RS, Chattopadhyay S, Norell MS, Pennell DJ and Senior R: The Heart Failure Revascularisation Trial (HEART). Eur J Heart Fail 13: 227-233, 2011.

9. Daubert MA, Massaro J, Liao L, Pershad A, Mulukutla S, Magnus Ohman E, Popma J, O'Neill WW and Douglas PS: High-risk percutaneous coronary intervention is associated with reverse left ventricular remodeling and improved outcomes in patients with coronary artery disease and reduced ejection fraction. Am Heart J 170: 550-558, 2015.

10. Mehan VK, Patil S and Patel M: An inexpensive, simple technique to improve the safety of femoral arterial puncture. Indian Heart J 67: 546-548, 2015. 
11. Matić DM, Ašanin MR, Stanković SD, Mrdović IB Marinković JM, Kočev NI, Antonijević NM, Marjanović MM, Nešić ZI, Prostran MS, et al: Incidence, predictors and prognostic implications of bleeding complicating primary percutaneous coronary intervention. Vojnosanit Pregl 72: 589-595, 2015.

12. Badings EA, Remkes WS, Dambrink JH, The $\mathrm{SH}$, Van Wijngaarden J, Tjeerdsma G, Rasoul S, Timmer JR, van der Wielen ML, Lok DJ, et al: Timing of intervention in high-risk non-ST-elevation acute coronary syndromes in PCI versus non-PCI centres : sub-group analysis of the ELISA-3 trial. Neth Heart J 24: 181-187, 2016.

13. He H, Li W, Qian W, Zhao X, Wang L, Yu Y, Liu J and Cheng J: Urinary interleukin-18 as an early indicator to predict contrast-induced nephropathy in patients undergoing percutaneous coronary intervention. Exp Ther Med 8: 1263-1266, 2014
14. Parodi G, Bellandi B, Xanthopoulou I, Capranzano P, Capodanno D, Valenti R, Stavrou K, Migliorini A, Antoniucci D, Tamburino C, et al: Morphine is associated with a delayed activity of oral antiplatelet agents in patients with ST-elevation acute myocardial infarction undergoing primary percutaneous coronary intervention. Circ Cardiovasc Interv 8: 126-128, 2014.

15. Wolny R, Pregowski J, Bekta P, Chmielak Z and Witkowski A: Early occlusion of the non-infarct-related coronary artery following successful primary percutaneous coronary intervention in ST-elevation myocardial infarction. Postepy Kardiol Interwencyjnej 11: 136-140, 2015. 